\title{
Chronic proximal spinal muscular atrophy of childhood and adolescence: problems of classification and genetic counselling
}

\author{
IRENA HAUSMANOWA-PETRUSEWICZ*, JACEK ZAREMBA†, AND \\ JANINA BORKOWSKA *
}

From the ${ }^{*}$ Department of Neurology, Medical School, and tDepartment of Genetics, Psychoneurological Institute, Warsaw, Poland.

\begin{abstract}
SUMMARY Results obtained from a study of 354 cases of chronic proximal spinal muscular atrophy of childhood and adolescence suggest that the condition is not as homogeneous as it was previously thought. A tentative classification based on our results is proposed. Estimates of genetic risks are provided, taking into account the sex and age at clinical onset. In our opinion these factors are more reliable than the data hitherto available because they are based on a considerably larger series.
\end{abstract}

The problem of the influence of sex in the chronic proximal form of spinal muscular atrophy (CPSMA) of childhood and adolescence based upon a study of 354 cases was discussed in our previous article published in this Journal. ${ }^{1}$ The information gathered during the study mentioned above allows us to comment on two other aspects, the classification of CPSMA and genetic counselling. The material and methods were described earlier. ${ }^{1}$

\section{Classification}

Until recently CPSMA of childhood and adolescence was considered to be a single condition, because there were no grounds for dividing it into different entities. ${ }^{23}$ We were even doubtful about the intermediate form of Fried and Emery ${ }^{4}$ being a separate entity (see No 25355 in McKusick $^{5}$ ). This problem was discussed in one of our earlier publications. ${ }^{6}$ However, our recent results ${ }^{17}$ suggest some heterogeneity of CPSMA. In this respect the subgroup with onset at 10 to 36 months of age was of particular interest because of a sharp and significant fall of the $p$ value of the segregation ratio (table 1, figure). It is possible that a large proportion of cases in this age range are phenocopies or new dominant mutations or both. They are distributed throughout the whole age spectrum of our material, but in the age range 10 to 36 months, in which there

Received for publication 27 September 1984. Accepted for publication 12 October 1984.
TABLE 1 Segregation ratios and empirical risk values according to sex in different age at onset subgroups of CPSMA of childhood and adolescence. ${ }^{*}$

\begin{tabular}{|c|c|c|c|c|c|c|c|c|}
\hline \multirow[t]{3}{*}{ Sex } & \multicolumn{8}{|c|}{ Age at onset } \\
\hline & \multicolumn{2}{|c|}{$0-9 \mathrm{mth}$} & \multicolumn{2}{|c|}{$10-36 \mathrm{mth}$} & \multicolumn{2}{|c|}{$37 m t h-8 y$} & \multicolumn{2}{|c|}{$9 y-18 y$} \\
\hline & $p$ & $r$ & $p$ & $r$ & $p$ & $r$ & $p$ & $r$ \\
\hline $\mathbf{M}$ & 0.25 & $1: 4$ & 0.036 & $1: 27$ & 0.22 & $1: 4 \cdot 5$ & $0 \cdot 20$ & $1: 5$ \\
\hline F & $0 \cdot 20$ & $1: 5$ & $0 \cdot 046$ & $1: 23$ & $0 \cdot 16$ & $1: 6$ & 0.00 & \\
\hline \multirow[t]{3}{*}{ All } & 0.22 & $1: 4 \cdot 5$ & 0.039 & $1: 25$ & $0 \cdot 19$ & $1: 5$ & 0.08 & $1: 12$ \\
\hline & \multicolumn{2}{|c|}{$0-24 \mathrm{mth}$} & \multicolumn{2}{|c|}{$25-18 y$} & \multicolumn{2}{|c|}{$37 m t h-18 y$} & \multicolumn{2}{|c|}{$0 y-18 y$} \\
\hline & $p$ & $r$ & $p$ & $r$ & $p$ & $r$ & $p$ & $r$ \\
\hline $\mathbf{M}$ & $0 \cdot 15$ & $1: 7$ & 0.20 & $1: 5$ & $0 \cdot 26$ & $1: 4$ & $0 \cdot 16$ & $1: 6$ \\
\hline F & $0 \cdot 15$ & $1: 7$ & $0 \cdot 12$ & $1: 8$ & 0.09 & $1: 11$ & $0 \cdot 14$ & $1: 7$ \\
\hline All & $0 \cdot 15$ & $1: 7$ & $0 \cdot 17$ & $1: 6$ & $0 \cdot 17$ & $1: 6$ & $0 \cdot 15$ & $1: 7$ \\
\hline
\end{tabular}

${ }^{*}$ More detailed data are given in tables 2 and 3 of our previous publication. ${ }^{1}$ $\mathrm{p}=$ segregation ratio. $\mathrm{r}=$ empirical risk.

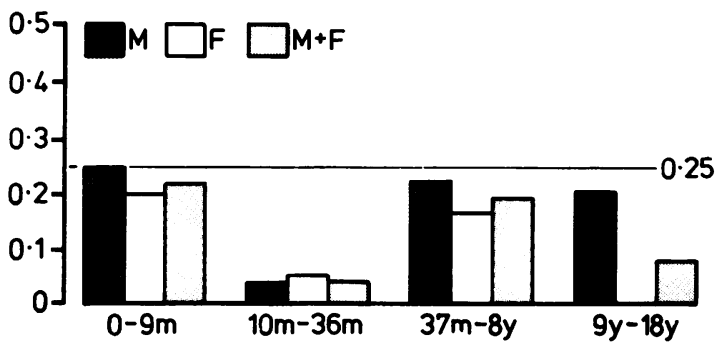

FIGURE Diagram of segregation ratios on four different age at onset subgroups (compare with table 1). 
may be only a few autosomal recessive cases, they become more evident. In one of our previous publications ${ }^{8}$ we considered the problem of dominant mutations and tried to explain their very infrequent occurrence $(0.75 \%$ in a large combined series of an international study on $\mathrm{SMA}^{9}$ ). However, we are now reconsidering our previous opinion because there is a possibility that most cases of the dominant form of juvenile SMA (No 15860 in McKusick $^{5}$ ) are new mutations, and that mild cases compatible with familial occurrence of this form of the disease are very rare, hence the apparent paucity of dominant cases of SMA. Most of them may never produce evidence of their dominance because of their greatly reduced fitness. Such cases may form an important part of the subgroup of SMA with onset at 10 to 36 months.

The basic defect of CPSMA and of other forms of SMA is not known and its clinical picture does not provide a sufficient basis for genetic classification. Therefore, we cannot be sure whether the condition we are dealing with constitutes a single entity or whether it is composed of several genetic entities. In view of the above data it is reasonable to assume that there may be three entities (table 2) as follows.

(1) The infantile chronic form characterised by age at onset usually between three and nine months with classic features of autosomal recessive inheritance with complete penetrance and the course of the disease tending to be milder in females. These cases constitute $51 \%$ of our material (see table 2 of our previous publication ${ }^{1}$ ). It should be stressed that the group of patients included here may overlap to some extent with the classic acute form of WerdnigHoffmann disease as defined by Pearn et $a l^{10}$ and Feingold et al. ${ }^{11}$ The subjects described by Pearn et a l' $^{12} 13$ under the term 'subacute and chronic SMA' correspond to our infantile chronic form, but includes also (2) and (3) below.

(2) The childhood isolated form $(32 \%$ of our cases) is characterised by onset usually between 10 to 36 months with a predominance of isolated cases. Most cases described as the intermediate form or type II of the disease ${ }^{414}$ appear to fit well with this form, both by the range of age at onset and by the very infrequent occurrence of familial cases. The segregation ratios in this form are not compatible with autosomal recessive transmission. The assumption that this subgroup contains many dominant mutations or some phenocopies or both is more plausible.

It should be noted that Fried and Emery ${ }^{4}$ assumed that this form is recessive and deliberately excluded from their material one family in which the condition was inherited as an autosomal dominant trait. Incidentally, in their study of 14 cases there was only one other family showing features of autosomal recessive transmission. By the criteria presented here, however, this family would be included in the first form because of the age at onset under nine months.

(3) The mild childhood and adolescent form (17\% of our cases) is characterised by age of clinical onset usually after the third year of life and autosomal recessive transmission with marked sex influence, expressed by a smaller proportion of affected females and consequently by a significant reduction of penetrance.

The classification and terminology of different forms of SMA are controversial. In McKusick ${ }^{5}$ the following three forms of proximal SMA appear to be relevant to our series. (Numbers in brackets are McKusick Catalogs numbers. ${ }^{5}$ ) (1) Muscular atrophy, juvenile (Kugelberg-Welander syndrome) (25 340*). (2) Muscular atrophy, spinal, intermediate type (25 355). (3) Muscular atrophy, juvenile (KugelbergWelander syndrome) (15 860*).

Initially we grouped them together because, as already stated, there were insufficient grounds for making a division. The clinical onset of CPSMA of childhood and adolescence, as our data show, may occur between birth and 18 years of life, but in our opinion there may be cases with onset of clinical expression in the early twenties. Forms 1 and 2, together with the acute form (see McKusick No 25 $330^{5}$ ), constitute the majority of SMA cases.

We have not included the acute form because most of our cases showed a protracted course.

*Conditions with mode of inheritance believed to be certain

TABLE 2 Proposed tentative classification of CPSMA of childhood and adolescence based upon analysis of 354 cases.

\begin{tabular}{lccc}
\hline Form of disease entity & Usual age at onset & Genetics & $\begin{array}{c}\text { Sex influence } \\
\text { presented material }\end{array}$ \\
\hline Infantile, chronic & $3 \mathrm{mth}-9 \mathrm{mth}$ & $\mathrm{R}$ & Slight \\
Childhood, isolated & $10 \mathrm{mth}-36 \mathrm{mth}$ & $\mathrm{D}$ mutations? & No evidence \\
Mild childhood and adolescence & $37 \mathrm{mth}-18 \mathrm{y}$ & Phenocopies? & $\mathrm{R}$ \\
\hline
\end{tabular}


According to Pearn et $a l^{10}$ and Feingold et $a l^{11}$ this is a distinct condition, although the available data are still ambiguous.

As we have said above, there is a possibility that some of the isolated cases in our material are new dominant mutations corresponding to form 3 (No $15860^{*}$ of $\mathrm{McKusick}^{5}$ ). Such cases in particular may constitute an important component of the subgroup with onset at 10 to 36 months (table 1 , figure).

Our data and those of other authors suggest that the following supplementary remarks and alterations in the Catalogs 5 might be justifiablet.

(1) A better delineation of the acute form $\left(25330^{*}\right)$, not only by the age at clinical onset but also by the age at death according to Pearn et $a l^{10}$ and Feingold $e t$ al, ${ }^{11}$ and naming it 'infantile acute form of Werdnig and Hoffmann'.

(2) Identifying the intermediate type of Fried and Emery ${ }^{4}$ with the 'infantile chronic' form described here (table 2) corresponding roughly to the form described by Pearn et $a l^{12} 13$ and adding an asterisk to the relevant No 25355 .

(3) Our 'childhood isolated' form (table 2) could be considered a possible dominant mutation, identical with that designated No $15860^{*}$ in the Catalogs. ${ }^{5}$

(4) A better delineation of juvenile SMA $\left(25340^{*}\right)$ corresponding to our form of 'mild childhood and adolescence' by the range of age at onset and by defining it as a sex influenced condition with reduced penetrance.

\section{Genetic counselling}

The estimation of genetic risk in CPSMA is

+We take the liberty of making these comments in response to Dr McKusick's statement in the foreword to the Catalogs, ${ }^{5}$ namely that he would appreciate any suggestions aimed at increasing the usefulness of the Catalogs. apparently a simple matter because, in general, the disease conforms to the autosomal recessive $\stackrel{\vec{D}}{\vec{D}}$ pattern of inheritance. However, our data strongly $\bar{r}$ suggest incomplete penetrance of the gene, because of the assumed 'female sparing factor' in higher age ranges, and therefore tentative values of empirical risk based on the $p$ values can be drawn for all ages of onset subgroups, for males and females separately (table 1).

Although CPSMA of childhood and adolescence is one of the more common genetic conditions, the data on estimates of empirical risk in this disease are scanty and based on small series. The published data available are those of Bundey and Lovelace ${ }^{15}$ and Pearn et al, ${ }^{12}$ the latter being quoted in the book The genetics of neurological disorders. ${ }^{16}$ In table 3 we give their risk figures together with the data from which they were drawn, as compared to our data in the same age ranges. A particularly low risk (1:15) was given by Bundey and Lovelace ${ }^{15}$ for the age at onset over 25 months. Pearn et al ${ }^{12}$ worked out the same value for 36 months onwards. We think that these figures are not reliable enough for genetic counselling in view of the very scanty series from which they were drawn. In the data of these authors, cases with age of onset over 36 months were hardly represented and a considerable proportion of the others could correspond to our subgroup of very low risk, that is, of 10 to 36 months.

Our results, although based on larger series, should also be treated with caution until more data are available. At present, the estimates of genetic risk presented in table 4 could be used for genetic counselling. If two or more sibs are affected the risk value of 1:4 should be given, independent of age at onset and sex, possibly with the exception of females in the subgroup 9 to 18 years if only male sibs were previously affected.

TABLE 3 Results of segregation analysis in CPSMA with consideration of the age at onset: comparison of the present results with those of other authors.

\begin{tabular}{|c|c|c|c|c|c|c|c|c|c|c|c|c|}
\hline \multirow[t]{3}{*}{ Age at onset } & \multicolumn{4}{|c|}{ Bundey and Lovelace ${ }^{15}$} & \multicolumn{4}{|c|}{ Pearn et $a^{l 2}$} & \multicolumn{4}{|c|}{ Present series (see also ref 1) } \\
\hline & \multirow{2}{*}{$\begin{array}{l}\text { No of } \\
\text { pro- } \\
\text { bands }\end{array}$} & \multicolumn{2}{|c|}{ No of sibs } & \multirow{2}{*}{$\begin{array}{l}p \\
(r)\end{array}$} & \multirow{2}{*}{$\begin{array}{l}\text { No of } \\
\text { pro- } \\
\text { bands }\end{array}$} & \multicolumn{2}{|c|}{ No of sibs } & \multirow{2}{*}{$\begin{array}{l}p \\
(r)\end{array}$} & \multirow{2}{*}{$\begin{array}{l}\text { No of } \\
\text { pro- } \\
\text { bands }\end{array}$} & \multicolumn{2}{|c|}{ No of sibs } & \multirow{2}{*}{$\begin{array}{l}p \\
(r)\end{array}$} \\
\hline & & Affected & Unaffected & & & Affected & Unaffected & & & Affected & Unaffected & \\
\hline Before $9 \mathrm{mth}$ & - & - & - & - & $?$ & 13 & 50 & $\begin{array}{l}0 \cdot 21 \\
(1: 5)\end{array}$ & 116 & 35 & 124 & $\begin{array}{l}0 \cdot 22 \\
(1: 5)\end{array}$ \\
\hline Before $24 \mathrm{mth}$ & 19 & 12 & 45 & $\begin{array}{l}0 \cdot 21 \\
(1: 5)\end{array}$ & - & - & - & - & 209 & 48 & 272 & $\begin{array}{l}0 \cdot 15 \\
(1: 7)\end{array}$ \\
\hline After $24 \mathrm{mth}$ & 14 & 2 & 27 & $\begin{array}{l}0 \cdot 07 \\
(1: 15)\end{array}$ & - & - & - & - & 61 & 17 & 86 & $\begin{array}{l}0 \cdot 17 \\
(1: 6)\end{array}$ \\
\hline $\begin{array}{l}36 \mathrm{mth} \text { and } \\
\text { later }\end{array}$ & - & - & - & - & $6(?)$ & 1 & 14 & $\begin{array}{l}0 \cdot 07 \\
(1: 15)\end{array}$ & 40 & 11 & 54 & $\begin{array}{l}0.17 \\
(1: 6)\end{array}$ \\
\hline Overall & 33 & 14 & 72 & $\begin{array}{l}0 \cdot 16 \\
(1: 6)\end{array}$ & 124 & 35 & 161 & $\begin{array}{l}0 \cdot 18 \\
(1: 6)\end{array}$ & 286 & 68 & 388 & $\begin{array}{l}0 \cdot 15 \\
(1: 7)\end{array}$ \\
\hline
\end{tabular}


TABLE 4 Empirical risk in CPSMA of childhood and adotescence based upon segregation analysis of 354 cases.

\begin{tabular}{llll}
\hline \multirow{2}{*}{ Age at onset } & \multicolumn{2}{l}{ Risk for next child (one already affected) } \\
\cline { 2 - 4 } & Males & Females & Overall \\
\hline $0-9$ mth & $1: 4$ & $1: 5$ & $1: 4$ to $1: 5$ \\
$10-36$ mth* & $1: 7$ & $1: 7$ & $1: 7$ \\
37 mth-8 y & $1: 4$ & $1: 6$ & $1: 5$ \\
9 y-18 y & $1: 5$ & Much lower & $1: 12$ \\
\hline
\end{tabular}

${ }^{*}$ As our data show (table 1) the actual risk in this age range may be as low as $1: 25$. However, until our results are confirmed it is safer to assume for this age range the risks which we obtained for the range 0 to $36 \mathrm{mth}$

tExact value unknown, probably not greater than 1:20.

The study was supported by a grant from the Polish Academy of Sciences 10.4.05.4.1.

\section{References}

1 Hausmanowa-Petrusewicz I, Zaremba J, Borkowska J, Szirkowiec W. Chronic proximal spinal muscular atrophy of childhood and adolescence: sex influence. $J$ Med Genet 1984;21:447-50.

2 Hausmanowa-Petrusewicz I, Askanas W, Badurska B, et al. Infantile and juvenile spinal muscular atrophy. J Neurol Sci 1968;6:263-87.

${ }^{3}$ Hausmanowa-Petrusewicz 1. Spinal muscular atrophy. Infantile and juvenile type. Warsaw: National Center for Scientific, Technical and Economic Information, 1978:111-28.

${ }^{4}$ Fried K, Emery AEH. Spinal muscular atrophy type II. A separate genetic and clinical entity from type I (WerdnigHoffmann disease) and type III (Kugelberg-Welander disease). Clin Genet 1971;2:203-9.

${ }^{5}$ McKusick VA. Mendelian inheritance in man. Catalogs of autosomal dominant, autosomal recessive and $X$-linked phenotypes. 6th ed. Baltimore, London: Johns Hopkins University Press, 1983.

${ }^{6}$ Hausmanowa-Petrusewicz I, Zaremba J, Borkowska J, Prot J. Genetic investigations on chronic forms of infantile and juvenile spinal muscular atrophy. J Neurol 1976;213:335-46.

7 Zaremba J. Genetics of the chronic, proximal form of the spinal muscular atrophy. Unpublished data, 1983.

${ }^{8}$ Hausmanowa-Petrusewicz I, Zaremba J, Borkowska J. Chronic forms of childhood spinal muscular atrophy. Are the problems of its genetics really solved? J Neurol Sci 1979;43:313-27.

9 Emery AEH, Davie AM, Holloway S, Skinner R. International collaborative study of the spinal muscular atrophies. Part 2. Analysis of genetic data. J Neurol Sci 1976;30:375-84.

10 Pearn JK, Carter CO, Wilson J. The genetic identity of acute infantile spinal muscular atrophy. Brain 1973;96:463-70.

"Feingold J, Arthuis M, Celeis J. Genetique de l'amyotrophie spinale infantile: existance de deux formes autosomique recessives. Ann Genet (Paris) 1977;20:19-23.

12 Pearn JH, Bundey S, Carter CO, Wilson J, Gardner-Medwin D, Walton JN. A genetic study of subacute and chronic spinal muscular atrophy in childhood. J Neurol Sci 1978;37:227-48.

${ }^{13}$ Pearn JH, Gardner-Medwin D, Wilson J. A clinical study of chronic childhood spinal muscular atrophy. J Neurol Sci 1978:38:23-37.

14 Dubowitz V. Infantile muscular atrophy. A prospective study with particular reference to a slowly progressive variety. Brain 1964;87:707-18.

15 Bundey S, Lovelace RE. A clinical and genetic study of chronic proximal spinal muscular atrophy. Brain 1975;98:455-71.

16 Baraitser M. The genetics of neurological disorders. New York: Oxford University Press, 1982:179-87.

Correspondence and requests for reprints to Professor Irena Hausmanowa-Petrusewicz, Neurological Department, Medical School, ul Lindleya 4, 02005 Warsaw, Poland. 